University of New Hampshire

University of New Hampshire Scholars' Repository

\title{
Human Papillomavirus (HPV) Vaccine: Attitudes, Behaviors, and Beliefs of At-Risk Women
}

\author{
Rosemary M. Caron \\ University of New Hampshire - Main Campus \\ Elisabeth Kispert \\ University of New Hampshire - Main Campus \\ Robert J. McGrath \\ University of New Hampshire, robert.mcgrath@unh.edu
}

Follow this and additional works at: https://scholars.unh.edu/hmp_facpub

Part of the Obstetrics and Gynecology Commons, Public Health Education and Promotion Commons, and the Women's Health Commons

\section{Recommended Citation}

R Caron, E Kispert, R McGrath. Human Papillomavirus (HPV) Vaccine: Attitudes, Behaviors, and Beliefs of At-Risk Women. The Internet Journal of Health. 2008 Volume 9 Number 2.

This Article is brought to you for free and open access by the Health Management and Policy at University of New Hampshire Scholars' Repository. It has been accepted for inclusion in Health Management and Policy Scholarship by an authorized administrator of University of New Hampshire Scholars' Repository. For more information, please contact Scholarly.Communication@unh.edu. 


\section{INTERNET SCIENTIFIC PUBLICATIONS}

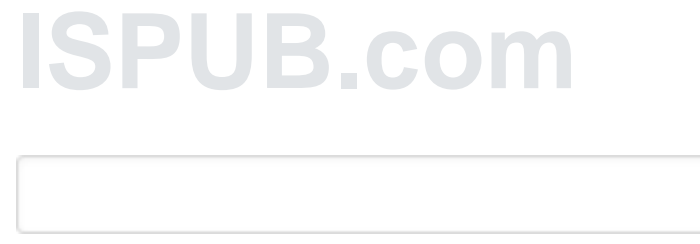

\section{HOME JOURNALS LATEST ARTICLES DISCLAIMERS ARTICLE SUBMISSIONS}

\section{CONTACT HELP}

The Internet Journal of Health

Volume 9

Number 2

Original Article

\section{Human Papillomavirus (HPV) Vaccine: Attitudes, Behaviors, and Beliefs of At-Risk Women}

R Caron, E Kispert, R McGrath

\section{Keywords}

cervix cancer, health education, hpv vaccine, human papillomavirus, public health, women's health

\section{Citation}

R Caron, E Kispert, R McGrath. Human Papillomavirus (HPV) Vaccine: Attitudes, Behaviors, and Beliefs of At-Risk Women. The Internet Journal of Health. 2008 Volume 9 Number 2.

\footnotetext{
Abstract

Cervical cancer is primarily caused by human papillomavirus (HPV) and is the second most common cause of cancer-related mortality among women. Female college students may be at risk for contracting HPV based on their sexual behavior. Following the release of the HPV vaccine, Gardasil $\circledast$, this cross-sectional study was developed to (1) determine awareness of HPV and Gardasil ${ }^{\circledR},(2)$ assess attitudes, behaviors, and beliefs about the HPV vaccine, and (3) identify information sources that female college students are accessing. Female college students voluntarily completed a self-administered questionnaire. Statistical analyses included descriptive statistics, Pearson's correlations and paired sample t-tests. Sexually active respondents would recommend the HPV vaccine to others and disagreed that vaccination would encourage risky sexual behavior. Correlations were identified on how self-reported knowledge influenced attitudes, behaviors, and beliefs regarding the HPV vaccine. These findings should assist in developing integrated public health education efforts for HPV vaccination that are targeted towards this at-risk population.
}

\section{Author Information}

Rosemary M. Caron, PhD, MPH

Associate Professor and Director of the Master of Public Health (MPH) Program in the Department of Health Management and Policy, College of Health and Human Services at the University of New Hampshire.

\section{Elisabeth Kispert, BS}

Graduate of the Department of Molecular, Cellular and Biomedical Sciences, College of Life Sciences and Agriculture at the University of New Hampshire.

Robert J. McGrath, PhD

Assistant Professor in the Department of Health Management and Policy, College of Health and Human Services at the University of New Hampshire.

\section{Share This Article}

Your free access to ISPUB is funded by the following advertisements: 


\section{Introduction \\ Background}

Cervical cancer is a global public health issue that is second to breast cancer in overall cancer-related mortality among women. Cervical cancer presents a distinctive public health challenge since it is caused by a sexually transmitted virus; is gender specific; and primary and secondary public health prevention efforts target an expansive age range of women. 1 According to the American Cancer Society, in the United States (U.S.), approximately 9,710 women were diagnosed with cervical cancer, and 3,700 died from this disease in 2006. 2 On a global level, approximately 500,000 cases of cervical cancer are diagnosed on an annual basis which accounts for approximately 250,000 deaths among women. 3-6

The majority of cervical cancer is caused by a persistent infection with the human papillomavirus (HPV). 7 The Papanicolaou (Pap) cytology test has proven to be an effective screening tool in identifying the precursor lesion associated with HPV infection. 8 HPV is a DNA virus with more than 100 different types having been identified; approximately 30 types are sexually transmitted. Low risk HPV types, HPV-6 and HPV11 , are responsible for $90 \%$ of genital warts cases. High risk HPV types, HPV-16 and HPV-18, account for approximately $70 \%$ of cervical cancer cases. $9 \mathrm{HPV}$ is one of the most common sexually transmitted infections in the world and studies suggest that approximately $90 \%$ of HPV infections resolve themselves within two years. It is the percentage of HPV infections that do not resolve themselves that have the potential to contribute to cervical cancer. 10,11 The prevalence of HPV has been found to be highest among young persons within the first few years after sexual activity is initiated. The prevalence of HPV infection was found to be highest among females aged 20-24 years. 12,13 Each year, approximately 6.2 to 7.5 million Americans become infected with genital HPV. The Centers for Disease Control and Prevention (CDC) reported that, unless vaccinated, approximately $80 \%$ of sexually active women will acquire HPV by the age of 50. 14

In June 2006, the Food and Drug Administration (FDA) approved the first prophylactic human papillomavirus vaccine, Gardasil ${ }^{\circledR}$, that has been shown to be effective against HPV types 6 and 11 which contribute to genital warts, and HPV types 16 and 18 which contribute to cervical cancer. Efficacy rates of the vaccine for clinical outcomes have approached $100 \%$ in preventing infection and disease in clinical trials of women aged 16 to 24. 15 The CDC's Advisory Committee on Immunization Practices currently recommends universal administration of three interval doses of the HPV vaccine, Gardasil ${ }^{\circledR}$, in girls 11 or 12 years of age. The recommendation also allows for females aged nine to 26 years to be vaccinated at the discretion of their physician. 16 Predictive public health strategies, such as administering the prophylactic HPV vaccine to all 12year-old girls in the U.S., estimate that more than 1,300 cervical cancer deaths among this susceptible population could be prevented. In addition, this public health approach could also prove to be cost effective if Pap tests were conducted at a later age and less frequently. Furthermore, a computer-based model estimated that HPV vaccination at age 12 and Pap tests every three years starting at age 25 could potentially reduce a woman's lifetime risk of cervical cancer by $94 \% .17,18$

\section{Purpose}

Early age of first sexual intercourse is associated with greater susceptibility to HPV 


\section{Internet Scientific Publications}

infection, possibly due to the immature status of the cervix. 19 In the U.S., sexual activity begins in ninth grade for $29.3 \%$ of girls, and $62.4 \%$ of twelfth grade girls report prior sexual activity. 20 Early sexual behavior warrants the importance of a prophylactic HPV vaccine for younger females, prior to becoming sexually active, in order to provide the most public health benefit. Furthermore, factors that have been associated with an increased risk of acquiring HPV include age, condom use, increasing cumulative number of sexual partners, sex with a new partner, knowing a partner less than a year, and marital status. $12,13,21,22$

HPV has been detected in $99.7 \%$ of cervical cancer cases. 7 Dunne et al. found the overall prevalence of HPV to be $26.8 \%$ in U.S. females aged 14 to 59 years and $24.5 \%$ among females aged 14 to 19, and HPV prevalence was $44.8 \%$ for females 20 to 24 years of age and $27.4 \%$ for females aged 25 to 29 years, and then decreased at older ages, possibly due to acquired immunity. 13 Moreover, several studies have shown that sexually active female college students in the 20-24 age group are often unaware of HPV and become aware of HPV only after being diagnosed with the HPV infection by a healthcare provider. 23,24 Thus, college age women may be at high risk for contracting HPV.

Kahn et al. explored the following variables in young women prior to the introduction of Gardasil ${ }^{\circledR}$ : knowledge about HPV and the HPV vaccine; personal beliefs about HPV vaccination; belief that others would approve of HPV vaccination; number of sexual partners; and perceived support of healthcare provider, partner, and parents. They found that all factors were significantly associated with the intention to receive the HPV vaccine. 25 Boehner et al. examined the acceptability of an HPV vaccine among college students several years before the HPV vaccine became available to the public and found that $74 \%$ of female college students would accept such a vaccine. 26 The purpose of our exploratory analysis is to expand upon this previous research by investigating, following the release of Gardasil ${ }^{\circledR},(1)$ what information sources female college students are accessing about the HPV vaccine; (2) how this knowledge has influenced attitudes, behaviors, and beliefs regarding the HPV vaccine among this population with respect to recommending the HPV vaccine to others, and whether or not receiving the HPV vaccine would encourage risky sexual behavior; and (3) correlations between social behavior (e.g., sexual practices, relationship status) and one's concern about HPV infection and recommending the HPV vaccine to others. This information, collectively, may offer different views on a pertinent health issue that health educators may want to consider as they develop integrated public health education and immunization initiatives aimed at reducing the burden of HPV infection among female college students.

\section{Methods}

A cross-sectional study design was utilized for this exploratory analysis, in order to administer a self-report questionnaire to a relevant sample of 361 female college students from a large, public, state-supported Northeastern university in 2007. The university's Institutional Review Board approved the study. Questionnaires were administered over a period of four weeks at different times and at several locations (e.g., University Health Services, Alpha Phi sorority, health class, aerobics class, and a choral rehearsal) on the university's campus from the end of February through March 2007. Questionnaires were also distributed on campus to female college students enrolled at the university who were entering or departing scheduled classes and events. The anonymous surveys took an average of seven minutes to complete and were immediately collected from the participants upon completion. University Health Services administered surveys to female students as they waited for their appointments. Completed surveys were returned to the reception desk and were collected in a locked collection box. 


\section{Internet Scientific Publications}

All questionnaires had a cover letter attached that explained the purpose of the study and emphasized the anonymity and confidentiality of the results. Students were told to keep this letter for their records. There were no incentives for participating in this study. Additional open ended comments from the participants were recorded at the end of the survey.

The 23-item questionnaire was designed to determine demographic information, level, and source of self-reported knowledge about HPV and the HPV vaccine and attitudes, behaviors, and beliefs about the HPV vaccine. Revisions were made during the pilot testing phase of the questionnaire. Ambiguities associated with the survey content were not identified during test trials that were conducted prior to official questionnaire administration.

Respondents were asked if they knew what HPV was and if they had heard of the HPV vaccine, Gardasil ${ }^{\circledR}$, prior to this survey ("Yes"/"No"/"Not sure" to both). In order to determine sources of information of the vaccine, respondents were asked to choose from the following sources: "Tell Someone" commercial, "One Less" commercial, talk show, news show, magazine advertisements, magazine articles, radio, newspaper articles, medical journals, Merck Pharmaceutical, Inc. web site, thehpvtest.com web site, general practitioner, nurse, other health professional, University Health Services, family, friends, and other. Respondents were instructed to circle all that applied to them.

Respondents were then asked if they would get the HPV vaccine if it were offered for free. Those who responded "No" or "Not sure" were asked a follow-up question to determine the reason for their response. There was also a question to determine what behavior changes have resulted from knowing about the HPV vaccine. Examples included: getting vaccinated against HPV; speaking with a healthcare professional about the HPV vaccine; sharing knowledge with family or friends; and engaging in further information gathering about the HPV vaccine and the link between cervical cancer and HPV.

Finally, information regarding the respondent's attitude about the idea that HPV vaccination may lead to risky sexual behavior, a current controversial topic, was collected. Respondents were asked a series of questions to determine the degree to which they agree with statements about the HPV vaccine, such as should females between the ages of nine and 26 years of age get the HPV vaccine, and whether or not they were personally concerned about acquiring HPV. The questions were analyzed on a three-point scale, "Agree"/"Disagree"/"Not sure."

All data were analyzed using the Statistical Package for Social Sciences (SPSS), Version 15.0 for Windows. Descriptive analyses were done for each of the following participant responses: specific college the participant was enrolled in at the university; age (age groups analyzed: 17-18, 19-21, 21-24, $\geq 25$ years); race; if have had sexual intercourse; age at which first had sexual intercourse; number of sexual partners (the number of sexual partners analyzed: $0,1,2,3-5, \geq 6$ ); condom use; relationship status; overall health status; if receive regular Pap screening tests; knowledge of HPV; heard of Gardasil ${ }_{\circledR}$ before survey; knowledge of the HPV vaccine; would get the HPV vaccine if it were offered for free; reasons for not getting the HPV vaccine if it were offered for free; behavior change(s) as a result of knowledge of the HPV vaccine; likelihood of recommending the HPV vaccine to others; agreement that females between the ages nine and 26 should get the HPV vaccine; belief that the HPV vaccine may encourage risky sexual behavior; and concern about possibly acquiring HPV.

Cross-tabulation analyses were done for the questions of interest and all demographic variables, as well as self-reported knowledge of HPV and the HPV vaccine. These 


\section{Internet Scientific Publications}

questions included: would get the HPV vaccine if it were offered for free; likelihood of recommending the HPV vaccine to others; agreement that females between the ages nine and 26 should get the HPV vaccine; agreement that HPV vaccination against a sexually transmitted infection may encourage risky sexual behavior; and concern about possibly acquiring HPV. Pearson's chi-square tests and two-tailed t-tests were done to assess relationships between two variables. For statistical tests, P-values less than 0.05 were considered to be statistically significant.

\section{Results}

The demographic and behavioral characteristics of female undergraduate respondents are shown in Table 1. Two hundred ninety-three of 361 surveys (81\% response rate) were completed and returned by female college students enrolled at a large Northeastern State University. Female students, aged 18 to 34 years, voluntarily participated in the anonymous study. The mean age of the respondents was 20.4 years (standard deviation [SD] $=0.125$ ), and $93.5 \%$ of respondents were Caucasian. Based on a comparison to information compiled by the university's Office of Institutional Research, the population demographics of our relevant sample are generalizable to the university's undergraduate female population due to the relative similarities of the sample characteristics for gender and ethnicity to that of the university population. Non-traditional female students and female graduate students were underrepresented.

\section{Figure 1}

TABLE 1. Demographic and behavioral characteristics of female undergraduate respondents 


\section{Internet Scientific Publications}

\begin{tabular}{|c|c|c|c|c|}
\hline Characteristics & $\% \quad n^{4}$ & Characteristics & $\%$ & $n^{e}$ \\
\hline Age & $\begin{array}{l}\text { Mean Age }= \\
20.4\end{array}$ & $\begin{array}{l}\text { Number of sexual partners in } \\
\text { your lifetime: }\end{array}$ & & \\
\hline Race & & 0 & 10.6 & 31 \\
\hline White & 93.5 & 1 & 21.5 & 63 \\
\hline Black/African American & 0.7 & 2 & 16.0 & 47 \\
\hline $\begin{array}{l}\text { American Indian/Alaskan } \\
\text { Native }\end{array}$ & 0.3 & 3.5 & 32.8 & 96 \\
\hline Asian & 2.4 & $\geq 6$ & 19.1 & 56 \\
\hline Two or more races & 2.0 & $\begin{array}{l}\text { How often do you and your } \\
\text { partner use a condom when } \\
\text { having sexual in tercourse? }\end{array}$ & & \\
\hline Other & 1.0 & Every time & 28.3 & 75 \\
\hline Religion & & Most of the time & 32.1 & 85 \\
\hline Christian & 37.9 & Sometimes & 21.5 & 57 \\
\hline Catholic & 40.3 & Hardly Ever & 12.8 & 34 \\
\hline Baptist & 0.3 & Never & 5.3 & 14 \\
\hline Jewish & 3.8 & $\begin{array}{l}\text { What is your current } \\
\text { relationship status? }\end{array}$ & & \\
\hline Other & 17.7 & Single & 33.8 & 99 \\
\hline $\begin{array}{l}\text { Do you actively practice } \\
\text { religion? }\end{array}$ & & Dating & 17.4 & 51 \\
\hline Yes & 37.9 & Monogamous relationship & 45.1 & 132 \\
\hline No & 62.1 & Married/living with partner & 3.8 & 11 \\
\hline Is religion important to you? & & Describe your health status: & & \\
\hline Yes & 64.7 & Excellent & 23.9 & 70 \\
\hline No & 35.5 & Very good & 57.3 & 168 \\
\hline $\begin{array}{l}\text { Have you ever had sexual } \\
\text { intercourse? }\end{array}$ & & Good & 17.7 & 52 \\
\hline Yes & 90.4 & Fair & 1.0 & 3 \\
\hline No & 9.6 & $\begin{array}{l}\text { What College are you } \\
\text { enrolled in? }\end{array}$ & & \\
\hline $\begin{array}{l}\text { Age at which you first had } \\
\text { sexual intercourse? }\end{array}$ & & Liberal Arts & 36.5 & 107 \\
\hline $13-15$ & 12.1 & $\begin{array}{l}\text { Engineering and Physical } \\
\text { Science }\end{array}$ & 3.1 & 9 \\
\hline $16-18$ & 68.7 & Life Science and Agriculture & 16 & 47 \\
\hline $19-22$ & 18.1 & Health and Human Services & 28.0 & 82 \\
\hline$\geq 23$ & 1.1 & Business and Economics & 9.9 & 29 \\
\hline $\begin{array}{l}\text { Do you get regular Pap } \\
\text { smears? }\end{array}$ & & Thompson School & 1.4 & 4 \\
\hline Yes & 78.8 & Graduate School & 4.1 & 12 \\
\hline No & 21.2 & Other & 0.6 & 2 \\
\hline
\end{tabular}

Note:

Total vanies due to selected questions left unanswered by respendent

The majority responded that they had previously had sex (90.4\%), and t-test results found the average age of women who responded "Yes" to previously having sex to be 20.5 and "No" to be $19.9(\mathrm{P}<0.014)$. T-test results showed that the majority of respondents did get regular Pap tests (78.8\%), and the mean age of those women who did get regular Pap tests (20.6) was statistically significant $(P<0.001)$ from those who did not (19.5). Also, the mean number of sexual partners among women who got regular Pap tests (4.6) was statistically significant $(\mathrm{P}<0.001)$ from those women who did not get regular Pap tests (2.4).

The majority of respondents both knew what HPV was (85\%) and had heard of the HPV vaccine, Gardasil $\circledast(85 \%)$, prior to completing this survey. The mean age of those who had heard of Gardasil ${ }^{\circledR}(20.4)$ was statistically different $(P<0.022)$ from those who were not sure (18.7). The majority of respondents who knew what HPV was had also heard of Gardasil ${ }^{\circledR}(92 \%)$, but there was some inconsistency. For instance, of the participants who did not know what HPV was, $28.6 \%$ had heard of Gardasil ${ }^{\circledR}$.

The most common sources of information about the HPV vaccine among respondents 


\section{Internet Scientific Publications}

were the "Tell Someone" television commercial (64.9\%) and the "One Less" television commercial $(64.5 \%)$, both of which were developed by Merck Pharmaceuticals, Inc. Friends (41.8\%) and family (31.9\%) were the next most common sources of information regarding the HPV vaccine.

The majority of respondents would get the vaccine if it were offered for free (75.3\%), and reasons for not getting the vaccine included "Need more information" (63.5\%) and "Safety concerns" (39.4\%). "Speaking to physician" (45.5\%) and "Sharing your knowledge with others" (41.6\%) were the most common behavior changes noted by respondents as a result of knowing about the HPV vaccine. There was a population of participants (16.2\%) who answered that they had begun the HPV vaccination series. The mean age for those "early adopters" was 19.7 years. There was a statistically significant correlation $(P<0.001)$ between those who had received the HPV vaccine and those who agreed that females between the ages of nine and 26 should get the HPV vaccine and were likely to recommend the vaccine to others.

We found several statistically significant associations between demographic variables and attitudes and behaviors with respect to the HPV vaccine. More than half of the respondents (52.9\%) marked that "Yes," they were concerned about possibly acquiring HPV. With cross-tabulation analysis, we found statistically significant associations between concern of acquiring HPV with each of the following variables: number of sexual partners $(P<0.029)$; knowledge of HPV $(P<0.002)$; if ever had sex $(P<0.001)$; and current relationship status $(P<0.001)$.

The majority of respondents (69.1\%) were likely to recommend that others be vaccinated against HPV. The mean age for those respondents who were likely to recommend the HPV vaccine $(20.4)$ was statistically different $(P<0.025)$ from those who were not likely to recommend the HPV vaccine (19.6). Statistically significant associations were also found between the likelihood of recommending the HPV vaccine and the following variables: knowledge of HPV $(P<0.001)$; knowledge of the HPV vaccine $(P<0.001)$; if ever had sex $(P<0.029)$; and if get regular Pap tests $(P<0.002)$.

A high percentage of respondents (82.8\%) agreed that females between the ages of nine and 26 should be vaccinated. Statistically significant associations with this statement were with knowledge of HPV $(P<0.006)$ and current relationship status $(P<0.022)$.

Finally, we addressed the controversial idea that vaccination against a sexually transmitted infection, specifically HPV, may encourage risky sexual behavior. The majority of respondents (65.3\%) disagreed with this idea. The mean age of respondents who disagreed (20.6) was statistically different $(P<0.03)$ from those who agreed (19.9). The most statistically significant correlations were found with this question and the following variables: knowledge of HPV $(P<0.001)$; knowledge of the HPV vaccine $(P<0.001)$; if ever had sex $(P<0.001)$; number of sexual partners $(P<0.021)$; age $(P<0.04)$; and if get regular Pap tests $(P<0.001)$ (Table 2).

\section{Figure 2}

TABLE 2. Characteristics of female undergraduate respondents and their belief that HPV vaccination may encourage risky sexual behavior 


\begin{tabular}{|c|c|c|c|c|c|c|c|}
\hline \multirow[t]{2}{*}{ Characteristics } & \multicolumn{2}{|c|}{ Agree } & \multicolumn{2}{|c|}{ Disagree } & \multicolumn{2}{|c|}{ Unsure } & \multirow[t]{2}{*}{$P$-value ${ }^{b}$} \\
\hline & $\%$ & $n^{4}$ & $\%$ & $n^{e}$ & $\%$ & $n^{4}$ & \\
\hline \multicolumn{8}{|l|}{$\begin{array}{l}\text { Do you know what } \\
\text { HPV is? }\end{array}$} \\
\hline Yes & 18.6 & 46 & 70.9 & 175 & 10.5 & 26 & $\mathrm{P}<.001$ \\
\hline No & 28.6 & 4 & 35.7 & 5 & 35.7 & 5 & \\
\hline Unsure & 40.0 & 12 & 33.3 & 10 & 26.7 & 8 & \\
\hline \multicolumn{8}{|l|}{$\begin{array}{l}\text { Ever had sexual } \\
\text { intercourse? }\end{array}$} \\
\hline Yes & 20.2 & 53 & 68.3 & 179 & 11.5 & 30 & $\mathrm{P}<001$ \\
\hline No & 32.1 & 9 & 35.7 & 10 & 32.1 & 9 & \\
\hline \multicolumn{8}{|l|}{$\begin{array}{l}\text { Number of sexual } \\
\text { partners in your } \\
\text { lifetime: }\end{array}$} \\
\hline 0 & 32.3 & 10 & 38.7 & 12 & 29.0 & 9 & $\mathrm{P}<021$ \\
\hline 1 & 19.0 & 12 & 63.5 & 40 & 17.5 & 11 & \\
\hline 2 & 17.0 & 8 & 66.0 & 31 & 17.0 & 8 & \\
\hline $3-5$ & 23.2 & 22 & 69.5 & 66 & 7.4 & 7 & \\
\hline$\geq 6$ & 18.2 & 62 & 65.3 & 41 & 13.4 & 39 & \\
\hline \multicolumn{8}{|l|}{ What is your age? } \\
\hline $17-18$ & 32.0 & 16 & 46.0 & 23 & 22.0 & 11 & $\mathrm{P}<.04$ \\
\hline $19-21$ & 19.8 & 35 & 67.2 & 119 & 13.0 & 23 & \\
\hline $22-25$ & 19.6 & 11 & 73.2 & 41 & 7.1 & 4 & \\
\hline$>25$ & 0.0 & 0 & 87.5 & 7 & 12.5 & 1 & \\
\hline \multicolumn{8}{|l|}{$\begin{array}{l}\text { Do you know what } \\
\text { the HPV vaccine is? }\end{array}$} \\
\hline Yes & 17.8 & 44 & 70.0 & 173 & 12.1 & 30 & $\mathrm{P}<, 001$ \\
\hline No & 36.6 & 15 & 41.5 & 17 & 22.0 & 9 & \\
\hline Not Sure & 100.0 & 3 & 0.0 & 0 & 0.0 & 0 & \\
\hline \multicolumn{8}{|l|}{$\begin{array}{l}\text { Do you get regular } \\
\text { Pap smears? }\end{array}$} \\
\hline Yes & 18.3 & 42 & 71.2 & 163 & 10.5 & 24 & $\mathrm{P}<, 001$ \\
\hline No & 32.3 & 20 & 43.5 & 27 & 24.2 & 15 & \\
\hline
\end{tabular}

Notes:

- Total varies due to selected questions left unanswered by respondent

b Pearson's chi-square test

\section{Discussion}

The public health benefits of HPV vaccination would be expected to significantly reduce HPV-related morbidity, treatment, and overall U.S. economic burden, which is estimated at more than $\$ 5$ billion annually. 27 In addition, the HPV vaccine also has the potential to prevent cervical cancer cases that are currently undetected due to a lack of Pap test screening. 9 Although this population of female college students surveyed had heard of HPV and the HPV vaccine, the lack of knowledge was the predominant reason respondents would not get the HPV vaccine even if it were offered for free. In order to dispel a false sense of security among this at-risk population, our findings warrant integrated public health efforts among health educators on college campuses and in the private sector, among parents and community health professionals, to name a few resources, with respect to HPV infection and cervical cancer control via health behavior education. These coordinated public health education strategies should involve primary (e.g., HPV vaccination) and secondary (e.g., screening and early detection) prevention methods to significantly reduce the burden of these preventable illnesses among this vulnerable female population.

Previous studies have shown that college students have very little knowledge about HPV. 


\section{Internet Scientific Publications}

28-30 In contrast, our results suggest that the majority (85\%) of female college students in our study do know what HPV is and have previously heard of the HPV vaccine, Gardasil ${ }^{\circledR}$. Interestingly, knowledge of HPV did not correlate directly to knowledge of the HPV vaccine. Conversely, $28.6 \%$ of women who did not know what HPV was, had heard of Gardasil ${ }^{\circledR}$. The "Tell Someone" and "One Less" television commercials developed by Merck Pharmaceuticals, Inc., were the most common sources of information about the HPV vaccine. Continued use of the media will be important to incorporate into future public health education and awareness efforts. While informing the viewer, the commercials also stress the importance of sharing knowledge with others. Family and friends were the next most common source of information about the HPV vaccine, and sharing knowledge with others was a behavior change noted by the respondents.

Our study results indicate strong correlations of self-reported knowledge about HPV and the HPV vaccine with the following themes:

Decision to get the HPV vaccine if it were offered for free. Although the majority $(75.3 \%)$ of women were likely to receive the HPV vaccine if it were offered for free, the remainder of women responded "No" or "Not sure." The most common reason for this was "Need more information." The respondents expressed that they do not feel they have enough information to decide to get the HPV vaccine, even if it were offered for free. The women also expressed concerns about safety of the HPV vaccine, which is understandable as Gardasil ${ }^{\circledR}$ is a new vaccine. Only 7\% responded that they "Do not think the HPV vaccine is important."

Likelihood of recommending the HPV vaccine to others and the belief that HPV vaccination will promote risky sexual behavior. Awareness of the HPV vaccine was another behavior that correlated significantly with the likelihood of recommending the vaccine to others and agreement that vaccination may encourage risky sexual behavior. Of those women who have heard of the HPV vaccine, $73.3 \%$ were likely to agree that others get the HPV vaccine. Of those women who had never heard of the HPV vaccine, $41.5 \%$ were likely to recommend it and $43.9 \%$ were not sure if they would recommend the HPV vaccine. In general, awareness of the HPV vaccine correlated with women being more likely to recommend the HPV vaccine and with disagreement that HPV vaccination may encourage risky sexual behavior. Interestingly, all of the women who were not sure what the HPV vaccine was were likely to recommend it and also agreed that HPV vaccination may encourage risky sexual behavior. This information suggests that these women may not view risky sexual behavior with a negative connotation since they are likely to recommend a vaccine that they think encourages risky sexual behavior.

Furthermore, the age of the respondents significantly correlated with agreement that HPV vaccination may encourage risky sexual behavior with older respondents disagreeing with this belief. These findings highlight the need for health behavior education regarding risky sexual activity and how to prevent HPV infection.

Agreement that females between the ages of nine and 26 should get the HPV vaccine. Interestingly, $82.8 \%$ of respondents agreed that females between the ages of nine and 26 should be vaccinated, as compared to "likely" recommending that others receive the HPV vaccine. This may very well be due to women not feeling informed enough to responsibly recommend that others receive the vaccine. However, when asked whether to agree or disagree, women felt more comfortable agreeing that females between the ages nine and 26 should be vaccinated.

Relationship status. Current relationship status of the respondents was a characteristic that provided statistically significant correlations with concern about possibly acquiring HPV and agreement that females between the ages nine and 26 should receive the HPV 


\section{Internet Scientific Publications}

vaccine. Of those women who were single or dating, the majority (56.1\% and $58.8 \%$, respectively) were concerned about acquiring HPV. Of those in monogamous relationships, 52.7\% were concerned about acquiring HPV. Of those respondents who were married or living with a partner, more than half (54.5\%) did not know or were not concerned about acquiring HPV. While women who are married or in a monogamous relationship may be at lesser risk for acquiring HPV, it is still a possibility. Therefore, this data emphasizes the importance of increased health educational awareness efforts, as women may be in high risk situations for acquiring HPV but not realize it. A majority of women, regardless of relationship status, agreed that females between the ages of nine and 26 should get the vaccine.

Sexual behavior and concern about possibly acquiring HPV. Of those women who previously had sexual intercourse, only slightly more than half $(56.5 \%)$ were concerned about acquiring HPV. This low percentage leads us to believe that women may know what HPV is, but they are not aware of the infectivity and prevalence of HPV, especially among women of these vulnerable ages. Of those women who previously had sexual intercourse, $70.2 \%$ were likely to recommend that others receive the HPV vaccine, and 68.3\% disagreed that HPV vaccination may encourage risky sexual behavior. Of those participants who had not had previous sexual intercourse, $60.7 \%$ were also likely to recommend that others receive the HPV vaccine, and $32.1 \%$ agreed that HPV vaccination may encourage risky sexual behavior. The data illustrates that sexual experience does significantly influence attitudes and behaviors toward the HPV vaccine.

Number of sexual partners. The number of sexual partners was another characteristic that provided statistically significant correlations. For example, with an increasing number of sexual partners from zero to more than six, there was an increase in the percentage of respondents who were concerned about acquiring HPV. A previous study found that HPV seropositivity increased with the number of sexual partners, from $10 \%$ with one partner, to $25 \%$ with two or three partners, and up to $53 \%$ with more than six partners. 31 Another study reported that each additional sexual partner added approximately $10 \%$ to the risk of acquiring HPV infection. 32 However, in our study, of those women who have had more than six sexual partners, $20 \%$ were not concerned about acquiring HPV. This is an alarming statistic that warrants the implementation of further public health HPV educational programs. It is possible that these women may feel comfortable with high-risk sexual activity if they believe they are protected from HPV infection by vaccination, hence a false sense of security. 30 In addition, there is a concern that an effective HPV vaccine would cause sexually active women to significantly reduce their adherence to obtaining Pap screening tests, thus leading to a potential increase in cervical cancer cases. 33 These findings, again, point to the need for vaccine availability to be accompanied by proper ancillary awareness education.

Risky behaviors. Furthermore, the age at which one first had sexual intercourse, condom use, description of health status, and race did not provide statistically significant correlations. However, the frequency distributions highlight risky behaviors among this vulnerable population. For example, 18.3\% of the respondents "Hardly ever" or "Never" used condoms with their male partners. Condom use has been associated with decreased risk of acquiring HPV among newly sexually active women. 21 The practice of not using condoms potentially puts these respondents at a higher risk for acquiring HPV infection.

Limitations. Although the findings from this exploratory analysis provide valuable insight into female college student attitudes, behaviors, and beliefs about HPV and the HPV vaccine, several limitations to this study should be noted. The sampling bias associated with a non-probability sampling technique is similar to other HPV studies in college 


\section{Internet Scientific Publications}

students and limits the generalizability of the findings from this study to female college students attending other universities. Yet, the sampling of female students in various classes and events provide enhanced representation. The sample characteristics were similar to the demographics of the university population and support the generalizability of findings for the sampled university. However, the findings cannot be applied to all female college students and may not be reflective of all young women. Future studies should use random samples from several universities to maximize the generalizability of the findings. Missing data occurred randomly across all surveys. In addition, the results were limited by the cross-sectional study design and compliance to the authenticity of self-reported information, such as HPV and HPV vaccine awareness. Despite these limitations, our findings have been appropriately qualified, and we propose that they provide valuable insight regarding selected correlates associated with sexual behavior and HPV vaccination. In addition, our findings warrant an educational intervention by health educators who may find this information useful when attempting to develop integrated public health education efforts that are targeted towards this at-risk population.

\section{Acknowledgment}

The authors are grateful to the respondents for participating in this study.

\section{References}

1. Pollack AE, Miranda B, Edouard L, et al. Ensuring access to HPV vaccines through integrated services: a reproductive health perspective. Bull World Health Organ.

2007;85(1):57-63.

2. American Cancer Society. Cancer facts and figures 2006. Available at http://www.cancer.org/downloads/STT/CAFF2006PWSecured.pdf. Accessed December 15, 2007.

3. Parkin DM, Bray FI, Devesa SS. Cancer burden in the year 2000. The global picture.

Eur J Cancer. 2001;37(suppl 8):S4-S66.

4. Katz IT, Wright AA. Preventing cervical cancer in the developing world. N Engl J Med. 2006;354:1110.

5. Schmiedeskamp MR, Kockler DR. Human papillomavirus vaccines. Ann Pharmacother. 2006;40:1344-1352.

6. Jacob M, Bradley J, Barone MA. Human papillomavirus vaccines: what does the future hold for preventing cervical cancer in resource-poor settings through immunization programs? Sex Transm Dis. 2005;32:635-640.

7. Walboomers J, Jacobs MV, Manos MM, et al. Human papillomavirus is a necessary cause of invasive cervical cancer worldwide. J Pathol. 1999;189(1):12-19.

8. Franco EL, Duarte-Franco E, Ferenczy A. Cervical cancer: epidemiology, prevention, and role of human papillomavirus infection. Can Med Assoc J. 2001;164:1017-1025. 9. Lowy DR, Schiller JT. Prophylactic human papillomavirus vaccines. J Clin Invest. 2006;116:1167-1173.

10. Moscicki AB, Shiboski S, Broering J, et al. The natural history of human papillomavirus infection as measured by repeated DNA testing in adolescent and young women. J Pediatr. 1998;132:277-284.

11. Franco EL, Villa LL, Sobrinho JP, et al. Epidemiology of acquisition and clearance of cervical human papillomavirus infection in women from a high-risk area for cervical cancer. J

Infect Dis. 1999;180:1415-1423.

12. Winer RL, Lee SK, Hughes JP, et al. Genital human papillomavirus: infection incidence and risk factors in a cohort of female university students. Am J Epidemiol. 2003;157:218-226.

13. Dunne EF, Unger ER, Sternberg M, et al. Prevalence of HPV infection among females in the United States. JAMA. 2007;297(8):813-819.

14. Centers for Disease Control and Prevention. General HPV infection - CDC fact sheet. http://www.cdc.gov/std/HPVISTDFactHPV.htm. Accessed December 15, 2007.

15. Food and Drug Administration. Gardasil (quadrivalent human papillomavirus [types 6, $11,16,18$ ] recombinant vaccine) [package insert]. Whitehouse Station, NJ, Merck \& Co; 2006. http://www.fda.gov/cber/label/HPVmer060806LB.pdf. Accessed December 15, 2007.

16. Centers for Disease Control and Prevention. Advisory Committee on Immunization Practices (ACIP). ACIP provisional recommendations for the use of quadrivalent HPV vaccine [Press release]. http://www.cdc.gov/nip/recs/provisional_recs/hpv.pdf. Accessed December 15, 2007.

17. Sanders GD, Taira AV. Cost effectiveness of a potential vaccine for human papillomavirus. Emerg Inf Dis. 2003;9(1):37-48.

18. Goldie SJ, Kohli M, Grima D, et al. Projected clinical benefits and cost-effectiveness 


\section{Internet Scientific Publications}

of a human papillomavirus 16/18 vaccine. J Natl Cancer Inst. 2004;96(8):604-615.

19. Kahn JA, Rosenthal SL, Succop PA, et al. Mediators of the association between age of first sexual intercourse and subsequent human papillomavirus infection. Pediatrics. 2202;109(1):E5

20. Eaton DK, Kann L, Kinchen S, et al. Youth risk behavior surveillance - United States, 2005. MMWR Surveill Summ. 2006;55:1-108.

21. Winer RL, Hughes JP, Feng Q, et al. Condom use and the risk of genital human papillomavirus infection in young women. N Engl J Med. 2006;354(25):2645-2654 22. Ho G, Bierman R, Beardsley L, et al. Natural history of cervicovaginal papillomavirus infection in young women. N Engl J Med. 1998;338(7):423-428.

23. Yacobi E, Tennant C, Ferrante J, et al. University students' knowledge and awareness of HPV. Prev Med. 1999;28:535-541.

24. Vail-Smith K, White DM. Risk level, knowledge, and preventive behavior for human papillomaviruses among sexually active female college students. J Am Coll Health. 1992;40:227-30.

25. Kahn JA, Rosenthal SI, Hamann T, et al. Attitudes about human papillomavirus vaccine in young women. Int J STD AIDS. 2003;14(5):300-306.

26. Boehner CW, Howe SR, Bernstein DI, et al. Viral sexually transmitted disease vaccine acceptability among college students. Sex Transm Dis. 2003;30(10):774-778. 27. de Melo-Martin I. The promise of the human papillomavirus vaccine does not confer immunity against ethical reflection. Oncologist. 2006;11:393-396.

28. Lambert EC. College students' knowledge of human papillomavirus and effectiveness of a brief educational intervention. JABFP. 2001;14(3):178-183.

29. Pitts M, Clarke T. Human papillomavirus infections and risks of cervical cancer: what do women know? Health Educ Res. 2002;17(6):706-714.

30. Dell DL, Chen H, Ahmad F, et al. Knowledge about human papillomavirus among adolescents. Obstet Gynecol. 2000;96:653-656.

31. Silins I, Kallings I, Dillner J. Correlates of the spread of human papillomavirus infection. Cancer Epidemiol Biomarkers Prev. 2000;9(9)953-9.

32. Shew ML, Fortenberry JD, Miles $P$, et al. Interval between menarche and first sexual intercourse related to risk of human papillomavirus infection. J Pediatr. 1994;125(4):661666.

33. Hymel PA. Decreasing risk: impact of HPV vaccination on outcomes. Am J Manag Care. 2006;12(17):S473-S482.

- \{full_citation\} 